\title{
Language and Communicative Functions as well as Verbal Fluency in Children with High-Functioning Autism
}

\author{
Aneta Rita Borkowska*
}

\author{
Department of Clinical Psychology and Neuropsychology, Institute of Psychology, University of Maria Curie \\ Sklodowska, Pl. Litwski 5, 20-080 Lublin, Poland
}

\begin{abstract}
The study was designed to investigate selected aspects of language and communicative functions as well as verbal fluency in children with HFA. The study group comprised 51 children, aged 10-12, including 23 subjects diagnosed with High-Functioning Autism, with normal IQ and able to communicate verbally, as well as a group of 28 controls. The applied tools included RHLB-PL Battery, a verbal fluency task and WISC-R Vocabulary subtest. The findings show significantly varied profiles of the investigated functions in the group of children with HFA. In comparison with their peers, they have greater difficulties drawing logical conclusions from stories. They find it difficult to grasp humour conveyed by linguistic expression and by metaphors, presented with the use of both linguistic materials and drawings. They have lower capacitates for understanding prosodic (emotional and language) aspects of utterances addressed to them. It has been established that they are able to correctly understand isolated words and recognize their designates despite the present distractors. No generalized deficits have been found in the subjects' verbal fluency. In comparison to the controls, the children with HFA generated similar number of words matching the phonemic criterion. Furthermore, their performance showed no perseverations, and comparably frequent clustering and switching. Lexicon matching the semantic criterion was more difficult to access for the children with HFA than for the controls. Children with HFA had difficulties in defining familiar words.
\end{abstract}

Keywords: Humour, prosody, metaphors, defining words, inferential language.

\section{INTRODUCTION}

Childhood autism is a neurodevelopmental disorder which, in accordance with contemporary diagnostic classifications, includes three groups of symptoms: impaired language and communication development, difficulties in social functioning as well as limited, stereotypical interests and behaviours [1].

Language development is perhaps the most important achievement in early childhood. The related competences open new possibilities in other areas of growth, i.e. in cognitive, social and emotional development. Due to this, symptoms of deficits in communication impact the development of social competences. Regardless of their profile, communication impairments will adversely impact the process of establishing social relations [2].

Autism is a broad diagnostic category, and children diagnosed with this disorder constitute an internally varied group [3]. This diversity relates to a number of factors, including the level of intelligence. Autistic children most frequently are also intellectually disabled, but there is also a clinical group diagnosed with HighFunctioning Autism (HFA). The term is applied to mild autistic symptoms without impairment in intellectual

*Address correspondence to this author at the Department of Clinical Psychology and Neuropsychology, Institute of Psychology, University of Maria Curie Sklodowska, PI. Litwski 5, 20-080 Lublin, Poland; Tel: +48815376057;

E-mail: aneta.borkowska@autograf.pl functioning where Intelligence Quotient is within the average range, i.e. over 85 [3]. Autistic children are also varied in terms of their functional language and communication capacities. Although the related impairments constitute a diagnostic criterion, the profiles of such dysfunctions are varied $[4,5]$.

The present study focuses on children with HighFunctioning Autism, who are known to differ in their performance of language tasks from the norm and from patterns characteristic for children with low-functioning autism. All children with HFA present with impaired verbal and non-verbal communication. Yet, review of literature suggests a hypothesis that the impairment does not affect all aspects of communication to the same degree and in fact some of them function in similar ways as in healthy individuals [6]. Autistic children start to speak later than their peers (at approximately 4-5 years of age), yet they have relatively large vocabulary. Unfortunately, they have difficulties understanding the precise meaning of words, particularly if it depends on the situation or social context. It is difficult for them to follow the sequence and meaning of conversation, and to maintain an appropriate distance from the interlocutor [7]. They frequently use model expressions acquired for example during classes. They do not learn generalized rules of grammar [5, 8]. Due to their impaired ability to grasp the meaning of syntactic forms they can more readily understand isolated words than if the same words are included in complete sentences. 
The areas which frequently are unimpaired include phonology and grammar of words [5]. On the other hand the findings related to the semantic aspect of language are ambiguous. The relative strengths include the development of vocabulary as well as understanding of and producing semantic associations. Semantic relations and abstract language are reported to be impaired; this is expressed by the tendency to literally understand information. Similarly, individuals with HFA tend to literally interpret irony and metaphors $[8,9]$. Another type of difficulty is related to humour appreciation, yet the relevant data available in the literature are rather scarce $[10,11]$. Ozonoff and Miller [12] have reported that individuals with HFA choose incorrect endings for jokes, which means they are not sensitive to linguistic humour. Other studies suggest that the ability to understand humour is not completely inaccessible to children with HFA. Small children may understand simple situational humour, and older children may achieve the ability to also understand certain forms of verbal humour. This depends on their intellectual level.

Research also suggests that individuals with HFA tend to have serious problems related to pragmatic aspects of language, which are manifested by lack of respect for the rules of conversation, unusual prosody and difficulties in adjusting to the situation, e.g. inconsiderate or rude behaviours, embarrassing questions $[8,9]$.

It is emphasized that the above difficulties may result from the general characteristics of information processing in children with HFA. Their processing of local and detailed information is better, while global and contextual processing seems to be rather limited.

Given the above ambiguities of previously reported findings, the present study was designed to identify the domains of language and communicative functioning which pose difficulties for children with HFA, and those in which these children do not face such problems.

\section{METHOD}

The study group comprised 51 children aged 10-12 (mean $10 ; 84, \mathrm{SD}=0,77$ ), including 40 boys and 11 girls. The clinical group consisted of 23 subjects diagnosed with High-Functioning Autism, with normal $\mathrm{IQ}$ and able to communicate verbally. The control group was made of 28 youngsters, aged 10-12 (mean $10 ; 90, S D=0,58), 7$ girls and 21 boys. The children in the clinical group were in the care of a facility for children and teenagers with autism; they had been diagnosed by a team of specialists, i.e. a psychologist, educationist, speech therapist and child psychiatrist. They met criteria for high functioning autism based on DSM-IVR.

The controls were selected specifically for the purpose of the study, i.e. they were matched to the clinical group for age, years of education (they were students at the same grade of school), level of intellectual development, socioeconomic status, family background and parents' education. These indicators were evaluated on the basis of a structured interview with the participants. It included questions on subjective assessment of the situation of the family, family structure and number of years of education of parents.

All individuals were featured by average intelligence (IQ in the clinical group $M=93.1$, in the control group IQ $M=95.2$, the difference was not statistically significant). All participants lived in complete families. In the criterion group $42 \%$ of parents had higher education, $48 \%$ secondary education and $10 \%$ vocational education, and in the control group $39 \%$ of parents had higher education, 53\% secondary education and $8 \%$ vocational education, the difference was not significant. In the criterion group, a good financial situation had $43 \%$ of families, an average had $51 \%$ of families and $6 \%$ had a poor financial situation, in a control group a good financial situation had $53 \%$ of families, an average $38 \%$ and $9 \%$ had poor financial situation, the difference between groups was not significant.Interviews with teachers and review of school documents were taken into account to exclude controls diagnosed with any impairments. Children's parents provided informed consent for their participation in the study.

\section{RESEARCH METHODS}

Assessment of communicative skills and pragmatic language was performed with the use of the Right Hemisphere Language Battery (RHLB), developed by Karen L. Bryan, and modified by E. Łojek (The Right Hemisphere Language Battery, RHLB-PL) [13]. It comprises eleven tests, with varied testing materials containing verbal descriptions of situations, pictures as well as recordings of nonsensical sentences. The essential quantitative indicators of the battery are based on scores acquired in the specific tests.

Test of Inferred Meaning Comprehension is designed to examine reading comprehension and the 
ability to draw conclusions about information given indirectly, based on the text and one's own general knowledge.

Lexical Semantic Test asks the subject to match words with their graphic equivalents. Performance of the task engages lexical semantic knowledge, phonemic hearing and visuospatial processing.

Humour Appreciation Test examines the ability to understand complex language and to perceive the joke implied by the text.

Commentaries Test is designed to assess the subject's behaviour in terms of spontaneity in providing remarks and comments.

Metaphor Picture Test examines the ability to understand verbally presented metaphors and match them with their pictorial equivalents. It enables assessment of abstract thinking based on visuospatial analysis of information.

Written Metaphor Test involves understanding of metaphors given in writing, and matching them with their linguistic explanations.

Explaining Metaphor Picture Tests involves the ability to explain a metaphor presented in a graphic form.

Explaining Written Metaphor Test asks subjects to explain in their own words a metaphor given in writing.

Emotional Prosody Test assesses the ability to understand intonation carrying emotions (happiness, sadness, and anger) expressed in nonsensical sentences.

Linguistic Prosody Test asks subjects to recognize the type of expression (question, statement, command) used in voicing the nonsensical sentences.

Discourse Analysis Test is designed to assess spoken interactions with others.

\section{Verbal Fluency}

Verbal fluency trials are commonly used in examining executive functions; they also enable assessment of mental lexicon. The present study used phonological and semantic verbal fluency tests, for words starting with the letter " $k$ " and the category of "animals", respectively. The subjects had 60 seconds to perform the trial; this duration is most frequently used in fluency tests. The following fluency rates were adopted:

1/ number of words generated for the applied phonemic criterion - words starting with the letter "k"

2/ number of perseverations, or repetitions, in words starting with the letter " $k$ "

3/ number of clusters in words starting with the letter "k"; a cluster was assumed to contain the minimum of three words

4/ number of switches in words starting with the letter " $k$ " - each change in the semantic category of the produced words

5/ number of words generated for the semantic criterion - animals

6/ number of perseverations in words generated for the criterion - animals

7/ number of clusters in words generated for the semantic criterion - animals; a cluster was assumed to contain the minimum of three words in one semantic category (e.g. birds, pets, aquatic animals, etc.) or in phonological category (e.g. animals whose names start with the letter "p")

8/ number of switches in words generated for the semantic criterion - animals; switch is any change in the category of the produced words (semantic or phonological)

\section{Defining Words}

The assumed measure of language functioning is the score in WISC-R Vocabulary subtest. It reflects the knowledge of words in Polish and the ability to define the meaning of words. The score makes it possible to identify subjects' ability to match words with semantic categories and to use abstract thinking and verbalization.

\section{RESULTS}

The findings related to communicative skills and pragmatic language in the children assed with RHLB$\mathrm{PL}$ are presented in Table 1.

Scores for Commentaries Test have not been included in the Table because only one commentary was contributed by the subjects in the clinical group. 
Table 1: Results of Assessment of Language and Communicative Competences and Comparison of the Clinical Group and the Controls (Standardized Results)

\begin{tabular}{|c|c|c|c|c|c|c|}
\hline \multirow{2}{*}{ RHLB subtest } & \multicolumn{2}{|c|}{ Clinical group } & \multicolumn{2}{|c|}{ Control group } & \multirow{2}{*}{ Z } \\
\cline { 2 - 5 } & Mean & SD & Mean & SD & \\
\hline \hline Test of Inferred Meaning Comprehension & 4.43 & 2.11 & 6.93 & 0.9 & -4.327 & 0.000 \\
\hline Lexical Semantic Test & 9.14 & 0.73 & 9.67 & 0.13 & 0.943 & n.i. \\
\hline Humour Appreciation Test & 1.10 & 0.76 & 1.89 & 0.32 & -4.136 & 0.000 \\
\hline Metaphor Picture Test & 0.71 & 0.84 & 1.96 & 0.19 & -5.256 & 0.000 \\
\hline Written Metaphor Test & 1.00 & 0.78 & 1.93 & 0.26 & -4.680 & 0.000 \\
\hline Explaining Metaphor Picture Tests & 0.86 & 0.85 & 2.57 & 0.63 & -5.238 & 0.000 \\
\hline Explaining Written Metaphor Test & 0.71 & 1.10 & 2.50 & 0.79 & -4.620 & 0.000 \\
\hline Emotional Prosody Test & 2.48 & 1.81 & 5.07 & 1.35 & -4.450 & 0.000 \\
\hline Linguistic Prosody Test & 2.95 & 1.96 & 4.86 & 1.69 & -3.269 & 0.001 \\
\hline
\end{tabular}

n.i.: no significant.

An analysis of the above results shows significant differences between the children with High-Functioning Autism and their healthy peers in the rates related to nearly all language and communication skills assessed by RHLB-PL battery. Lexical semantic subtest is an exception, as both groups achieved similar scores.

Verbal fluency was the second aspect of language functioning which was examined.

The data presented in the Table 2 shows that some indicators differentiated the two groups and some of them suggested similar abilities in children with HFA and their healthy peers. The main indicator, i.e. the number of generated words shows no differences between the groups in the case of the phonological criterion; conversely, in the semantic criterion children with HFA generated significantly fewer words than the controls.

The rate for the number of perseverations in both groups and in both criteria was very low, less than one word, yet statistical analyses showed that in

Table 2: Comparison of Scores in Verbal Fluency in the Study Groups

\begin{tabular}{|c|c|c|c|c|c|c|}
\hline \multirow[t]{2}{*}{ Verbal fluency indicator } & \multicolumn{2}{|c|}{ Clinical group } & \multicolumn{2}{|c|}{ Control group } & \multirow[t]{2}{*}{$\mathbf{Z}$} & \multirow[t]{2}{*}{$\mathbf{P}$} \\
\hline & Mean & SD & Mean & SD & & \\
\hline $\begin{array}{l}\text { 1/ Number of words generated for the applied } \\
\text { phonological criterion - words starting with the letter "k" }\end{array}$ & 7.01 & 3.50 & 10.74 & 3.98 & 1.931 & n.i. \\
\hline $\begin{array}{l}\text { 2/ Number of perseverations in words starting with the } \\
\text { letter " } k \text { " }\end{array}$ & 0.30 & 0.41 & 0 & 0 & -2.13 & 0,03 \\
\hline $\begin{array}{l}\text { 3/ Number of clusters in words starting with the letter } \\
\text { "k" }\end{array}$ & 1.1 & 0.89 & 0.60 & 0.75 & -1.48 & n.i. \\
\hline $\begin{array}{l}\text { 4/ Number of switches in words starting with the letter } \\
\text { "k" }\end{array}$ & 5.24 & 3.49 & 9.20 & 4.03 & -2.90 & 0,001 \\
\hline Rate of switches in words starting with the letter "k" & 1.337 & 1.002 & 1.167 & 0.98 & 0.875 & n.i. \\
\hline $\begin{array}{l}\text { 5/ Number of words generated for the semantic } \\
\text { criterion - animals }\end{array}$ & 11.48 & 4.25 & 16.35 & 3.90 & -3.181 & 0,001 . \\
\hline $\begin{array}{l}\text { 6/ Number of perseverations in words generated for the } \\
\text { criterion - animals }\end{array}$ & 0.45 & 0.83 & 0.30 & 0.45 & 0.52 & n.i. \\
\hline $\begin{array}{l}\text { 7/ Number of clusters in words generated for the } \\
\text { criterion - animals }\end{array}$ & 1.43 & 1.12 & 1.75 & 1.25 & -0.77 & n.i. \\
\hline $\begin{array}{l}\text { 8/ Number of switches in words generated for the } \\
\text { criterion - animals }\end{array}$ & 8.57 & 4.40 & 12.15 & 4.12 & -3.17 & 0,001 \\
\hline $\begin{array}{l}\text { Rate of switches in words generated for the criterion - } \\
\text { animals }\end{array}$ & 1.339 & 0.965 & 1.345 & 0.946 & 0.043 & n.i. \\
\hline
\end{tabular}

n.i - no significant. 
phonological criterion children from the clinical group tended to more often repeat words produced earlier

Because the number of switches depends on the total number of generated words, the table additionally presents the rate of switches, which is the relation of all generated words to the number of switches. The rates of switches in both phonological and semantic category suggest the two groups did not differ in terms of the applied strategies.

Another aspect of language function examined during the trials was the knowledge of words and the ability to define them either by matching them with a superior category, or by identifying their significant qualities, purpose or function. The clinical group obtained the mean result $(M=7.01 ; S D=5.39)$ which was significantly lower than in the control group $(M=11.18 ; S D=3.54)(z=-3.086, p=0.03)$. Children with HFA were found with significantly poorer knowledge of and ability to define words.

\section{DISCUSSION}

The study was designed to determine whether at the age matching late childhood, subjects with diagnosed High-Functioning Autism show deficits in language and communicative function and in verbal fluency. Of all pervasive developmental disorders HighFunctioning Autism has been explored least thoroughly by researchers, and due to this the present study has focused on this clinical group.

The findings show that the children with HighFunctioning Autism significantly differ from their healthy peers in the rates illustrating nearly all language and communication skills, which were accessed with the use of RHLB-PL battery. Children with HFA answered significantly fewer questions related to texts, which required comprehension of inferred meaning, and this suggests difficulties in drawing logical conclusions based on linguistic material. This result confirms those which have been published previously on inferential thinking in HFA [14]. That kind of deficit can cause some adaptive problems of everyday communication [15].

Children from the clinical group significantly less frequently picked funny endings for verbally presented stories, and tended to provide concrete answers matching the literal content, which can be interpreted as a difficulty in understanding the humour contained in short stories, but at the same time fully understand the literal meaning. Humour appreciation is relatively rarely examined in children with HFA [11]; hence the present findings seem to be important for our in-depth understanding of social difficulties experienced by these children.

The HFA participants scored lower in tasks in which they were asked to explain a metaphor, either by choosing one or by providing an interpretation in their own words; this confirms deficits in abstract thinking [16]. They were also significantly less successful in language and emotional prosody tasks, like in other studies $[6,8,17]$. No differences were found between the two groups only in lexical semantic subtest where the subjects were expected to understand isolated words and recognize their designates in drawings (among a number of distractors of varied nature). The findings show that the subjects with HFA are able to perform this type of language task without problems, which means they effectively function at the level of understanding isolated words. This result supports suggestions brought forth by earlier publications $[5,16$, 18].

The verbal fluency test is a complex task in which the subject is required to apply a strategy of exploring his/her mental lexicon; it also enables the assessment of executive functions [19-21]. The findings have only partly confirmed the assumed deficit related to this aspect of development, due to the fact that some results indeed do differentiate the two groups while others show the same skills in children with HFA and the healthy controls. The main indicator, i.e. the number of generated words shows that performance of the subjects with HFA in the task of phonemic verbal fluency was similar to that of the healthy controls, which is inconsistent with findings reported by other researchers [20]. These suggested that deficits related to lexicon exploration are common. The task of semantic fluency turned out to be more difficult for the subjects with HFA: they generated significantly fewer words than the controls, what is contrary to Begeer et al. [4], who obtained the equal numbers of total words produced in a autism and a control group. Our results might be a confirmation of a semantic deficit in this clinical group although the impairment in verbal fluency tasks in the HFA group, Speka et al. [21] explained by the relatively low processing speed found in this group.

The number of generated words shows whether or not the subject can easily access his/her mental lexicon and has the ability to look for adequate words, required by the situation, and this is a significant indicator of 
executive functions [19, 22]. The present findings suggest that difficulties in accessing one's lexicon depend on the requirements of the task and do not constitute a generalized deficit.

Another significant performance indicator in a fluency task is the number of perseverations, which is linked with working memory function and reflects the ability to control the course of information processing. The rate in both groups and for both criteria was very low, less than one word. The result differentiating the two groups, shown by statistical analysis, seems to be of lesser importance for interpretation due to the very low number of perseverations in both groups. This finding is consistent with other publications suggesting that the function of cognitive inhibition is retained in HFA, and a lack of tendency for perseverations in a fluency task is evidence of this.

Clustering and switching are indicators showing that subjects employ the strategy of exploring their mental lexicon and are aware of its structure. Because the number of switches depends on the total number of generated words, an additional "rate of switches" was used to present the relation of all generated words to the number of switches. Both switching problems and a lack of use of strategy can be hypothesized for individuals with HFA [23]. The rates of switches in both categories suggest the two groups did not differ in terms of the applied strategies. These results confirm those which have been published [21, 24].

Contrary to Dennis, Lazenby and Lockyer [14], in our study children with HFA face more difficulty than their healthy peers in defining familiar words, even though their scores are within the broad range of results accepted as normal.

The study of language in HFA children is a complex task because of the diversity of the language skills in that clinical group. Specific pattern of skill and impairment have been reported in each of the domains of language [25]. That is why the language exploration in a greater detail is needed to better understand clinical picture of individuals with HFA.

\section{CONCLUSIONS}

The children with HFA participating in the present study represent varied profiles of language and communication competences. Their strengths include good comprehension of isolated words, ability to seek out adequate words, explore mental lexicon as required by circumstances, and to monitor the process of linguistic performance. Their weaknesses are linked with the capacity to use abstract, non-literal language, to infer meaning implied by linguistic material, to formulate definitions and to understand prosodic aspects of communication.

\section{CLINICAL EXAMPLE}

Bartek (9 years and 11 months) with HFA, during RHLB-PL trial obtained maximum scores in three subtests, namely: lexical semantic, humour appreciation and written metaphor. This means he was able to correctly recognize a graphic realistic designate of a concept (word), i.e. distinguish it from graphically or semantically similar drawings. He can also correctly process emotional contents (understands funny endings), is capable of abstract thinking which is manifested in the way he understands metaphors if their explanations are presented verbally. On the other hand, Bartek completely failed in the Metaphor Picture Test; in each task he pointed to a concrete drawing suggesting literal explanation of the metaphors. In both metaphor picture and written metaphor test he was asked to give three explanations but provided only one. Comparison of his performance in the comprehension task of choosing a correct interpretation and in the task which asked for his own explanations suggests the boy can sense the abstract meaning of the metaphor but it is too difficult for him to provide an interpretation in his own words.

In Emotional Prosody test Bartek had problems understanding the emotional component of communications (sadness, anger and happiness), yet he did not have any difficulties in Language Prosody test and successfully performed all the tasks. This means he correctly picked the intentions contained in questions, statements and commands.

The boy also coped well with Inferred Meaning Comprehension subtest, where he scored 6 out of 8 points; this result was similar to that achieved by the controls, and better than the average in the clinical group. This means Bartek understands the message of texts consisting of a few sentences; he can analyze them and draw logical conclusions based on that.

An analysis of Bartek's score in verbal fluency test shows that the number of words generated by him (starting with the letter "k" -8 words) is similar to the average in the control group and higher than in the clinical group. This suggests average access to mental 
lexicon. Qualitative analysis of the provided words shows that they are mainly linked with daily life. The lack of perseverations shows good working memory and the ability to control what is being said, and in his performance we can see frequently applied strategy of switching. This suggests an ability to smoothly shift to a new subcategory, but also a difficulty in accessing various designates within broad categories of concepts (number of clusters $=0$ ).

In tasks examining knowledge and ability to define concepts the boy acquired 8 converted points, and this is a score similar to the mean in the clinical group (7), yet interpretation of this result leads to a conclusion the score is in the broad range of average results classified as normal.

\section{REFERENCES}

[1] Simonoff E, Pickles A, Charman T, Chandler S, Lucas T, Baird G. Psychiatric disorders in children with autism spectrum disorders: prevalence, comorbidity and associated factors in population-derived sample. J Am Acad Child Adolesc Psychiatry 2008; 47(8): 921-29. http://dx.doi.org/10.1097/CHI.0b013e318179964f

[2] Rybakowski F, Białek A, Chojnicka I, et al. Autism spectrum disorders - epidemioogy, symptoms, comorbidity and diagnosis. Psychiatr Pol 2014; 48(4): 653-665.

[3] Geier DA, Kern J, Geier MR. A prospective cross-sectional cohort assessment of health, physical, and behavioral problems in autism spectrum disorders. Maedica (Buchar) 2012; 7(3): 193-200.

[4] Begeer S, Wierda M, Scheeren AM, Teunisse J-P, Koot HM, Geurts HM. Verbal fluency in children with autism spectrum disorders: Clustering and switching strategies. Autism 2014; 18: 81014-8.

http://dx.doi.org/10.1177/1362361313500381

[5] Pisula E. The autistic mind in the light of neuropsychological studies. Acta Neurobiol Exp 2010; 70: 119-30.

[6] Landa RJ, Goldberg MC. Language, Social and executive functions in High Functioning Autism: A Cintinuum of Performance. J Autism Dev Disord 2005; 35: 557-73. http://dx.doi.org/10.1007/s10803-005-0001-1

[7] Bryńska A. Semantic functions in Asperger Syndrome. Warsaw: Medical University Press 2012.

[8] Arciuli J. Prosody and autism. In: Arciuli J, Brock J, Eds. Communication in Autism. Amsterdam: John Benjamins Publishing Co. 2014; pp. 103-24.

[9] Pijnacker J, Hagoort P, Buitelaar J, Teunisse J-P, Geurts B. Pragmatic Inferences in High-Functioning Adults with Autism and Asperger Syndrome. J Autism Dev Disord 2009; 39: 607-618.

http://dx.doi.org/10.1007/s10803-008-0661-8

[10] Reddy V, Williams E, Vaughan A. Sharing humour and laughter in autism and Down's syndrome. Br J Psychol 2002; 93: 219-42.

http://dx.doi.org/10.1348/000712602162553
[11] Lyons VV, Fitzgerald M. Humor in Autism and Asperger Syndrome. J Autism Dev Disord 2004; 34: 521-31. http://dx.doi.org/10.1007/s10803-004-2547-8

[12] Ozonoff S, Miller JN. An exploration of right-hemisphere contributions to the pragmatic impairments of autism. Brain and Language 1996; 52: 411-34.

http://dx.doi.org/10.1006/brln.1996.0022

[13] Łojek E. The Right Hemisphere Language Battery - polish version (RHLB-PL). Warsaw: Pracownia Testów Psychologicznych PTP 2007.

[14] Dennis M, Lazenby AL, Lockyer L. Inferential language in high-functioning children with autism. J Autism Dev Disord 2001; 31(1): 47-54. http://dx.doi.org/10.1023/A:1005661613288

[15] Puiga O, Calvoa R, Rosaa M, et al. Verbal Memory and IQ Predict Adaptive Behavior in Children and Adolescents with High-Functioning Autism Spectrum Disorders. Intellect Disabl Diagn J 2013; 1: 22-27. http://dx.doi.org/10.6000/2292-2598.2013.01.01.4

[16] Zielińska M, Sterczyński R, Bagińska A. The Profile of WISC$\mathrm{R}$ Scores in Children with High-Functioning Autism. Psychiatr Pol 2014; 48: 667-76.

[17] Diehl JJ. Prosody Comprehension in High-functioning Autism. Rochester: University of Rochester 2007.

[18] Roberts JMA. Echolalia and language development in children with autism. In: Arciuli J, Brock J, Eds. Communication in Autism. Amsterdam: John Benjamins Publishing Co. 2014; pp. 75-102.

[19] Henry JD, Crawford JR. Ameta-analytic review of verbal fluency deficits in schizophrenia relative to other neurocognitive deficits. Cogn Neuropsychiatry 2005; 10: 133.

http://dx.doi.org/10.1080/13546800344000309

[20] Kleinhans N, Akshoomoff N, Delis DC. Executive Functions in Autism and Asperger's Disorder: Flexibility, Fluency, and Inhibition. Dev Neuropsychol 2005; 27: 379-401. http://dx.doi.org/10.1207/s15326942dn2703 5

[21] Speka A, Schatorjéa T, Scholte E, van Berckelaer-Onnes I. Verbal fluency in adults with high functioning autism or Asperger syndrome. Neuropsychologia 2009; 47: 652-6. http://dx.doi.org/10.1016/j.neuropsychologia.2008.11.015

[22] Liss $M$, Fein $D$, Allen $D$, et al. Executive functioning in highfunctioning children with autism. J Child Psychol Psychiatry 2001; 42: 261-70. http://dx.doi.org/10.1111/1469-7610.00717

[23] Reverberi C, Laiacona M, Capitani E. Qualitative features of semantic fluency performance in mesial and lateral frontal patients. Neuropsychologia 2006; 44: 469-78. http://dx.doi.org/10.1016/j.neuropsychologia.2005.05.011

[24] Koolen A, Vissers CThWM, Hendriks AWCJ, Egger JIM, Verhoeven L. The Interplay between Attentional Strategies and Language Processing in High-functioning Adults with utism Spectrum Disorder. J Autism Dev Disord 2012; 42: 805-14.

http://dx.doi.org/10.1007/s10803-011-1310-1

[25] Wilkinson KM. Profiles of language and communication skills in autism. MRDD Research Reviews 1998; 4: 73-9. 